\title{
Is academic performance of medical students dictated by their gender and ethnicity?
}

\author{
Indira Adiga K ${ }^{1}$, Chandrika Dinesh Nayak ${ }^{1,}$ Surekha Bhat $M^{2}$, Asha Kamath ${ }^{3}$
}

Identification of factors affecting academic performance of students is an ongoing research conducted with the intention of helping weaker students. 'Do gender and ethnicity of students affect their academic performance?' is a question asked by many teachers time and again (Haqet al, 2005, Alfan \& Othman, 2005).

Undergraduate medical course at Melaka Manipal Medical College (MMMC), Manipal, India is unique as students of three different ethnicities (Chinese, Indian and Malay) study together. At MMMC, we observed a variation in the academic performance of students between the two genders and the three ethnicities. Therefore, a study was undertaken among the first year undergraduate students to analyze their essays and multiple true/ false (MTF) scores (out of maximum 55 and 30 respectively) in Biochemistry theory examination (continuous assessment) to validate our observation. Students of three consecutive admissions (batches 22, 23 and 24) consisting of 116, 117 and 103 respectively were included in the study. Analysis was carried out with SPSS software using one way analysis of variance (ANOVA). Among the batch 22 students, mean scores of females were significantly higher than that of males in essay $(p<0.001)$ and MTF $(p<0.01)$ papers. However, this difference was not noted in the other two batches involved in the study. When analysis was carried on pooled samples of all three batches, the difference in the performance based on gender was not significant. Chinese students were better than Indians and Malaysians in essay and MTF papers. This difference of 3.82 marks in essay $(p<0.01)$ and 2.27 marks in MTF $(p<0.001)$ were significant between Chinese and Malay students. Though the performance of Indian students was intermediate compared to Chinese and Malay students, these differences were not statistically significant. Our study clearly shows that Chinese students performed significantly better than Malays, the reason for which needs to be explored. This work will be useful to the interested parties who are keen on improving medical students' performances.

\section{References}

Alfan, E. \& Othman, M. N. (2005) "Undergraduate students' performance: the case of University of Malaya", Quality Assurance in Education, 13 (4), pp.329 -343.

Haq, I.,Higham, J., Morris, R. \& Dacre, J. (2005) Effect of ethnicity and gender on performance in undergraduate medical examinations, Med Edu, 39 (11), pp.1126-8.

${ }^{1}$ Department of Biochemistry,

Melaka Manipal Medical College, Manipal Campus India

2. Department of Biochemistry,

Foundation in Science, Melaka Manipal Medical College, Melaka Campus, Malaysia

${ }^{3}$ Community medicine,

Kasturba Medical College, Manipal University, India 